\title{
Transitory Debt: Evidence from Borsa Istanbul
}

\author{
Emrah Arioglu ${ }^{1}$, Turgut Curuk $^{1} \&$ Yildirim Beyazit Onal ${ }^{1}$ \\ ${ }^{1}$ Cukurova University, Turkey \\ Correspondence: Emrah Arioglu, Cukurova University, Turkey. E-mail: earioglu@cu.edu.tr
}

Received: October 9, 2013

Accepted: October 22, $2013 \quad$ Online Published: January 10, 2014

doi:10.5430/ijfr.v5n1p11

URL: http://dx.doi.org/10.5430/ijfr.v5n1p11

\begin{abstract}
In this study, we investigate whether or not there is any behavior of publicly listed firms at Borsa Istanbul supporting the predictions of transitory debt model. For this purpose we investigate the leverage behavior of a subsample of firms that increase their leverage levels substantially. Our findings suggest that firms deviate from target leverage levels as a result of substantial debt increases. This behavior of firms contradicts the predictions of tradeoff theory, and supports the predictions of transitory debt model. In US financial markets, the main motivation for firms to deviate from target leverage levels deliberately but temporarily through transitory debt is suggested as investment purposes. In contrast, our findings suggest that firms substantially increase their leverage levels with the main motivation of working capital purposes, followed by investment purposes, in Turkish economy.
\end{abstract}

Keywords: tradeoff theory, transitory debt, Borsa Istanbul

\section{Introduction}

Numerous studies investigating the capital structure behavior of firms listed on Borsa Istanbul suggest that the behavior of these firms is consistent with tradeoff theory (Arslan, 2005; Ata \& Ag, 2010; Sayilgan \& Uysal, 2011; Arioglu \& Tuan, 2013). In addition to the studies investigating Borsa Istanbul, Fama and French (2002), Leary and Roberts (2005), Flannery and Rangan (2006), Kayhan and Titman (2007), Huang and Ritter (2009), Harford et al. (2009) provide global evidence supporting the predictions of the tradeoff theory. The tradeoff theory's main predictions are that firms would have optimal capital structures as a consequence of the trade-off between the potential benefits and costs of debt, and that managers would adjust firms' leverage levels towards the optimal capital structure, in order to maximize firm value.

On the other hand, more recently DeAngelo et al. (2011) estimate a capital structure model, which investigates whether or not firms deviate from optimal capital structures, and if they do what the main motivation underlying these deviations is. They name this model "transitory debt model". In transitory debt model, firms employ debt as a transitory financing vehicle. The debt helps firms meet funding needs that arise as a result of imperfectly anticipated investment shocks. The model predicts that firms would temporarily but deliberately deviate from target capital structures by issuing transitory debt. The prediction of transitory debt model contradicts the predictions of tradeoff theory. Recently, Denis and Mckeon (2012), and Gombola and Arioglu (2013) provide evidence supporting the prediction of transitory debt model. These studies suggest that the main motivation underlying the temporary deviations from target capital structures is firms' investments. In other words, even if firms follow target capital structures, they deviate from these targets deliberately but temporarily when they have valuable investment opportunities.

In this study, we investigate whether or not there is any behavior of publicly listed firms at Borsa Istanbul supporting the predictions of transitory debt model. We also investigate if publicly listed firms deliberately but temporarily deviate from target capital structures, what the main motivation underlying this behavior is. More specifically, do firms publicly listed at Borsa Istanbul deviate from target capital structures when they have valuable investment opportunities or for other purposes? It should be interesting to test the predictions of transitory debt model in an economy like Turkish economy since the common practice of financing investments for firms is mostly through rolling over short term debt due to the scarcity of long term debt, unlike more developed countries.

In developed economies such as US economy it might not be very surprising to observe that firms would issue transitory debt and increase their leverage levels when they have valuable investment opportunities. However, in Turkish economy, the common practice of financing investments for firms is mostly through rolling over short term 
debt due to the scarcity of long term debt. For firms in our sample we find the median short term debt to total debt ratio as $65.70 \%$, in nontabulated results. Thus, firms could be expected to fund their investments in current assets and working capital rather than long term investments, for maturity matching purposes. Thus, the investigation of the validity of the predictions of transitory debt model would shed light into the financing behavior of firms publicly listed at Borsa Istanbul and it would be interesting to observe whether the short term preference regarding debt issues would be reflected onto investment horizon of these firms.

We conduct our analysis by investigating substantial leverage increases by non-financial firms publicly listed on Borsa Istanbul between the years 1998 and 2010. Our preliminary findings suggest that firms prefer to make majority of their investments in current assets, rather than fixed assets. Based on these figures, we can suggest that firms prefer to have current assets, and thus prefer to use short term financing in their financing decisions, which is validated by data, for maturity matching purposes. This behavior could potentially provide us with leverage increase motivation results that are different than those observed in studies covering US markets.

However, before we investigate the main motivation for firms' substantially increasing their leverage levels, we investigate the behavior of their leverage levels. What we observe is that firms' median market leverage ratios increase from $16.49 \%$ in year t-3 to a level of $24.52 \%$ in the year prior to the substantial leverage increase. At the time of the substantial leverage increase, the median market leverage ratio jumps to a high level of $45.75 \%$ and stays over $40 \%$ in the following three years. These findings would be expected as a result of the nature of the substantial leverage increasing firms subsample.

What is more interesting is the pattern of the median excess leverage levels, which shows the deviation of leverage levels from target leverage levels. We observe that the excess market leverage levels start decreasing three years before the substantial leverage increase and make a substantial jump at the time of the substantial leverage increase, to a high level of $19.02 \%$. It is important to note that these findings suggest that firms could be valuing the option to borrow and thus, prior to substantial leverage increases, they decrease their leverage ratios even below their target leverage levels to maintain excess debt capacity, contradicting the predictions of tradeoff theory.

In order to further investigate the behavior of the market leverage levels in more detail, we also conduct two bootstrap simulations. The confidence intervals derived by both simulations suggest that the leverage levels of firms in substantially leverage increasing sample deviate from target leverage levels. This behavior of firms, in terms of issuing debt causing them to deviate from target leverage levels do not fit the predictions of tradeoff theory. However, their behavior is in accordance with the transitory debt model.

The next and the last step of our analysis is to investigate the motivation underlying the substantial leverage increase that causes these firms to deviate from target leverage levels, as opposed to the predictions of tradeoff theory. The results of our analysis suggest that firms substantially increase their leverage levels with the main motivation of working capital purposes, by half of the firms in the subsample, followed by investment purposes, by $31 \%$ of the firms in the subsample. Based on our findings, we can suggest that, firms in Turkish economy are more likely to prefer short term debt in their debt structure, in order to invest in current assets, and they issue transitory debt in order to fund their investments in current assets and working capital rather than long term investments, for maturity matching purposes.

\section{Data and Methodology}

Our sample includes firms traded at Borsa Istanbul between the years 1998 and 2010. We collect data from COMPUSTAT global annual database. The database gathers financial data for firms publicly listed on Borsa Istanbul through financial statements submitted to Borsa Istanbul by the publicly listed firms. Our sample excludes firms missing data necessary for leverage calculations and financial firms. This leaves us with a final sample of 148 firms. However, not all the firms in the sample have all the observations for the whole sample period. This leaves us with an unbalanced panel data.

For our analysis, we calculate firms' market leverages. We follow the calculations employed by Flannery and Rangan (2006) and Denis and McKeon (2012). Market leverage is calculated as the sum of LTD and DiCL, divided by the sum of LTD, DiCL and SP times NofS. LTD is total long term debt, DiCL is the debt in current liabilities, SP is the common share price at year end, and NofS is the number of common shares outstanding.

Alternatively, we also calculate book leverage, which is defined as the sum of long term debt, and current debt divided by total assets. When we conduct our analysis using this definition, our findings are parallel to those derived by employing market leverage, thus we do not report results derived by using book leverage. In addition, Rajan and Zingales (1995) calculate leverage using an alternative definition. This definition includes items as accounts payable 
in total liabilities, which does not fit our focus of active capital structure choices of firms. Therefore, we prefer not to employ this alternative specification in our analyses.

The focus of this study is the main motivation underlying displacements from target leverage levels. Thus, we need a proxy for long run target leverage, since it is not observable. For this purpose, we predict the target market leverage ratio using a double-sided tobit regression model censored at 0 and 1 for each year. In this specification, actual market leverage is regressed on a set of independent variables, which are suggested by Frank and Goyal (2009) as the most reliable factors in explaining leverage. The regression model we use, based on Denis and McKeon's (2012) model, is:

$$
\begin{aligned}
\text { Leverage }_{i t}= & \alpha+\beta_{1}(\text { Med. Ind. Leverage })_{\mathrm{i}, \mathrm{t}-1}+\beta_{2}(\mathrm{M} / \mathrm{B})_{\mathrm{i}, \mathrm{t}-\mathrm{1}}+\beta_{3}(\mathrm{FA} / \mathrm{TA})_{\mathrm{i}, \mathrm{t}-1}+\beta_{4}(\mathrm{OI} / \mathrm{TA})_{\mathrm{i}, \mathrm{t}-1}+ \\
& \beta_{5}[\ln (\mathrm{TA})]_{\mathrm{i}, \mathrm{t}-\mathrm{1}}+\varepsilon
\end{aligned}
$$

In the above specification, $\mathrm{M} / \mathrm{B}$ is the market-to-book value of assets ratio (proxy for growth options), Operating Income to Total Assets ratio (OI/TA) is the proxy for profitability, Med. Ind. Market Leverage is the median industry market leverage, Fixed Assets to Total Assets ratio (FA/TA) is the proxy for asset tangibility, and $\ln (\mathrm{TA})$ is the natural logarithm of total assets as a proxy for firm size. Market-to-book ratio is defined as the ratio of market value of assets to book value of assets. To calculate FA/TA we divide Property Plant \& Equipment by Total Assets. OI/TA is calculated by dividing Operating Income Before Depreciation by Total Assets.

We estimate separate annual regressions in our model, which allows us to avoid incorporating expected inflation into the model. The reason is that expected inflation will be uniform across all firms each year. In addition, we use the lagged values of the independent variables in order to have causality from independent variables to the dependent variable.

We present the descriptive statistics for the firms in our sample in Table 1, which shows that the mean book leverage value is 0.214 , whereas the mean market leverage value is 0.280 . The median industry book leverage on average is 0.197 , whereas the median industry market leverage on average is 0.247 . The mean $\mathrm{M} / \mathrm{B}$ ratio of assets is 1.322 , the mean $\mathrm{Ln}(\mathrm{TA})$ is 5.908 , the mean FA/TA is 0.338 and the mean OI/TA is 0.118 . The variables presented in Table 1 and utilized throughout the paper are winsorized at $1 \%$ and $99 \%$.

As mentioned before, we are interested in firms that deviate from target leverage levels through substantial leverage increases. Thus, we need to identify firms, which increase their leverage levels substantially through transitory debt. In order to be identified as a substantially leverage increasing firm, a firm needs to satisfy three requirements. It needs to have increased its market leverage at least $10 \%$ compared to the prior year's level. It also needs to have a new market leverage that is at least $10 \%$ above the target leverage that we have predicted. In addition, the firm is required to have increased its leverage ratio as a result of a debt increase, and not an equity decline. To be able to identify these firms, following Denis and McKeon (2012), we calculate a new variable $\$ \Delta M L$ which is calculated as: the difference of total debt for period $t$, and the product of total debt for period t- 1 and the ratio of market value of assets of period $t$ and market value of assets of period $t-1$.

By using this calculation and setting a requirement that the change in debt is equal to at least $90 \%$ of $\$ \Delta \mathrm{ML}$, we are able screen out the firms that did not have the leverage increase as a result a debt increase, but did actually have an equity decline. The firms that satisfy all of the three requirements for a given year are identified in our substantially leverage increase subsample. After identifying substantially leverage increasing firms, the next steps are to investigate whether firms deviate from target leverage levels through these substantial leverage increases and to investigate the motivation underlying this substantial debt increase.

Table 1. Descriptive statistics (1998-2010)

\begin{tabular}{lcc}
\hline & Panel A: Descriptive Statistics & \\
\hline Book Leverage & Mean & Standard Deviation \\
Market Leverage & 0.214 & 0.228 \\
Med. Ind. Book Leverage & 0.280 & 0.278 \\
Med. Ind. Market Leverage & 0.197 & 0.109 \\
Market-to-Book Value of Assets & 0.247 & 0.182 \\
Ln(TA) & 1.322 & 0.767 \\
FA/TA & 5.908 & 1.821 \\
OI/TA & 0.338 & 0.195 \\
\hline
\end{tabular}


The table presents the descriptive statistics for the firms publicly listed on Borsa Istanbul between the years 1998 and 2010. The firms covered are non financial firms, with data necessary for leverage calculations. The sample period covers 1160 firm year observations. Book leverage is the sum of long term debt and current debt divided by total assets. Market leverage is the sum of long term debt and debt in current liabilities divided by the sum of long term debt, debt in current liabilities, and number of common shares outstanding multiplied by common share price at year end. Median industry book and market leverages are the median values for industry book and market leverages, and are represented by MIBL and MIML, consecutively. $\mathrm{Ln}(\mathrm{TA})$ is the natural logarithm of total assets, FA/TA is Property Plant \& Equipment divided by Total Assets. OI/TA is Operating Income Before Depreciation divided by Total Assets.

Once the substantially leverage increasing firms are identified, we conduct two bootstrap confidence interval analyses to formally investigate whether these firms deviate from target leverage levels through substantial debt increases. We investigate whether firms' median market leverage levels lie within the bootstrapped confidence intervals of the median target leverage levels. If the answer to this question is "yes", then we can suggest that firms deviate from their target leverage levels through transitory debt issues and continue with the investigation of the main motivation underlying substantial leverage increases.

The first bootstrap confidence intervals for the median target leverage levels are derived by applying the percentile intervals method. In this method we first randomly sample the median target leverage levels of substantially leverage increasing firms, with replacement, for 1000 times. In order to figure out the $95 \%$ confidence intervals for the median target leverage levels, we select the bootstrap estimates, which lie on the $2.5 \%$ and $97.5 \%$ percentile. We bootstrap the confidence intervals in this manner for the year three year preceding the substantial leverage increase, the year of the increase and the three years following the increase.

The confidence percentile intervals might be criticized for estimating biased bootstrap estimates compared to the original estimate, and also for the potential that the standard errors will vary with the value of the estimate. To overcome these two potential problems, we also derived the bias corrected and accelerated (BCa) confidence intervals for the median target leverage levels. This method utilizes the bias correction and acceleration statistics in deriving the confidence intervals.

We next turn our attention to the potential motivations underlying substantial debt issues. Funding investment outlays and capital expenditures, avoiding reductions in dividends, covering operational cash shortfalls, paying out to stockholders, funding working capital increases are suggested as the potential main purposes of debt issues in prior literature (Healy \& Palepu, 1990; DeAngelo et al., 2011; Denis \& McKeon, 2012). Based on this list, in order to investigate the main motivation for the transitory debt issue by substantially leverage increasing firms, we identify four potential motivations: (i) operations, (ii) payout, (iii) working capital, and (iv) investment. For our calculations regarding each motivation, we follow the calculations employed by Denis and McKeon (2012), with slight changes to fit Turkish accounting procedures.

Operations (OCF) cover the use of equity proceeds from the IPO for covering operational cash shortfalls. It is calculated as:

$$
\text { Operating Cash Flow }=\text { OANCF }- \text { RECCH }- \text { INVCH }- \text { APCH }- \text { ACCLI }- \text { AOLOCH }+ \text { EXRE }
$$

where RECCH is accounts receivable (decrease), INVCH is inventory (decrease), APCH is accounts payable/creditors (increase), ACCLI is accrued liabilities (increase), AOLOCH is other assets \& liabilities (other change), OANCF is operating activities (net cash flow) and EXRE is exchange rate effect. Unlike Denis and McKeon's (2012) OCF calculations, we do not include accrued taxes in our calculations since it is not a common practice applied by Turkish publicly listed firms. When OCF is negative, it is treated as use of equity proceeds for the purpose of covering operational cash shortfall. When OCF is a positive figure, it is used in the analysis as zero.

The other potential motivation underlying substantial leverage increase that we investigate is payout purposes. Payout covers the equity proceeds used for the purpose of paying out to stockholders. Following Healy and Palepu (1990) and Denis and McKeon (2012), we assume that during any year, the expected amount for paying out to stockholders is equal to the dividend paid in the previous year. Thus, our payout value reflects the deviations from expected payout. In this sense payout is equal to the difference between the sum of dividends and repurchases in year $\mathrm{t}$ and the dividends in year $\mathrm{t}-1$.

Another potential motivation underlying substantial leverage increase is Working Capital purposes. Working capital value that we calculate covers the change in working capital $(\Delta \mathrm{WC})$ that is used for funding working capital needs. It is calculated as below: 


$$
\triangle \mathrm{WC}=\mathrm{CHECH}-\mathrm{RECCH}-\mathrm{INVCH}-\mathrm{APCH}-\mathrm{ACCLI}-\mathrm{AOLOCH}-\mathrm{IVSTCH}-\text { FIAO }
$$

where $\mathrm{CHECH}$ is cash \& cash equivalents (increase), IVSTCH is short term investment (change) and FIAO is financing activities (other).

The last potential motivation underlying substantial leverage increase that we investigate is investment purposes. The investment figure that we calculate covers the funds used for investment opportunities. To calculate Investment (I), we first calculate net investment which includes all cash used for investment activities, and from this figure we subtract the capital expenditures of the prior year, thus having cash used for funding increases in investments. The figure is calculated as below:

$$
\mathrm{I}=\mathrm{CAPX}+\mathrm{AQC}+\mathrm{IVCH}-\mathrm{PSFIX}-\mathrm{SIV}-\mathrm{IVACO}
$$

where PSFIX is proceeds from sale of fixed assets, SIV is sale of investments, IVCH is increase in investments, CAPX is capital expenditures, AQC is acquisitions, and IVACO is investing activities (other).

After calculating the values for each potential uses of debt issue proceeds classes, the next step is to determine the dollar value of proceeds from the debt issue. Then we divide the values of each class by this amount, to calculate the percentages of the debt issue proceeds attributed to each class. Then we sum the percentages of each four classes up. If any class makes up for $50 \%$ of the total percentage of the four classes in the equity proceed, that class is defined as the primary use of the equity proceeds. By employing this methodology, we are able to identify a total of 64 substantial leverage increase firm observations and for 57 of them we are able to identify a main motivation underlying the debt issue. We present and discuss our results in the following section.

\section{Results}

As mentioned in the previous section, we are able to identify 64 firm observations that make substantial leverage increases during the 1998-2010 period. For 57 of these firm observations, we are able to identify the main motivation for the substantial leverage increase. We first present the descriptive statistics for the substantially leverage increasing firms subsample in Table 2.

In Table 2, we observe the evolution of median total assets, total debt, market equity, FA/TA, OI/TA and market-to-book ratios for substantially leverage increasing firms. $t$ denotes the year of the substantial leverage increase. When we consider the evolution of total assets around the time of the leverage increase, we do not observe any substantial fluctuations. On the other hand, as a natural outcome of the design of the sample, we observe a substantial increase in debt levels at the time of the substantial leverage increase. On the other hand, the levels of market value of equity fluctuate throughout the observation period. However, at the time of the substantial leverage increase, the figure does not increase; but actually decreases from a year ago. This is an indication of achievement of meeting the third criteria of identifying substantially leverage increasing firms.

The median ratio of fixed assets to total assets evolves around approximately $30 \%$ through the substantial leverage increase period. These figures also provide us with a hint of the asset maturity choices of firms at Borsa Istanbul. Based on these figures, we can suggest that firms prefer to have current assets, compared to fixed assets in their asset composition and thus could potentially prefer to use short term financing in their financing decisions for maturity matching purposes. This behavior could potentially provide us with leverage increase motivation results that are different than those observed in studies covering US markets. When we look at the median operating income to total assets ratio, we observe that this ratio declines at the time of the substantial leverage increase. In addition, a similar pattern is observed in terms of the evolution of median market-to-book ratios.

Table 2. Descriptive statistics for substantially leverage increasing firms (1998-2010)

\begin{tabular}{lrrrrrrr}
\hline & $\mathbf{t}-\mathbf{3}$ & $\mathbf{t}-\mathbf{2}$ & $\mathbf{t}-\mathbf{1}$ & $\mathbf{t}$ & $\mathbf{t + 1}$ & $\mathbf{t + 2}$ & $\mathbf{t + 3}$ \\
\hline In(Total Assets) & 5.91 & 6.32 & 6.47 & 6.76 & 6.81 & 6.85 & 7.08 \\
Total Debt & 63.08 & 107.65 & 128.25 & 323.75 & 322.25 & 284.32 & 289.97 \\
Market Equity & 317.64 & 413.94 & 457.86 & 421.07 & 425.35 & 382.09 & 565.97 \\
FA/TA & 0.277 & 0.321 & 0.323 & 0.358 & 0.351 & 0.311 & 0.341 \\
OI/TA & 0.131 & 0.122 & 0.101 & 0.076 & 0.076 & 0.084 & 0.096 \\
Market-to-book & 1.330 & 1.228 & 1.213 & 1.063 & 1.049 & 1.055 & 1.110 \\
\hline
\end{tabular}


The table presents the descriptive statistics for substantially leverage increasing firms publicly listed on Borsa Istanbul between the years 1998 and 2010. The firms covered are non financial firms, with data necessary for leverage calculations. The sample period covers 57 substantially leverage increasing firms. In order to be identified as a substantially leverage increasing firm, a firm needs to satisfy three requirements. It needs to have increased its market leverage at least $10 \%$ compared to the prior year's level. It also needs to have a new market leverage that is at least $10 \%$ above the target leverage that we have predicted. In addition, the firm is required to have increased its leverage ratio as a result of a debt increase, and not an equity decline. $t$ denotes the year of the substantial leverage increase. $\operatorname{Ln}(\mathrm{TA})$ is the natural logarithm of total assets, FA/TA is Property Plant \& Equipment divided by Total Assets. OI/TA is Operating Income Before Depreciation divided by Total Assets. Market-to-book ratio is the ratio of market value of assets to book value of assets. Total debt and market equity are denoted in million Turkish Liras.

Next, we present our findings regarding the evolution of market leverage ratios, target market leverage ratios and excess market leverage ratios for substantially leverage increasing firms. According to tradeoff theory, these firms would be expected to increase their leverage levels in order to follow target leverage levels. Thus, deviations from target leverage levels, namely excess leverage levels, should not be observed. The findings are presented in Table 3 .

Table 3. Evolution of leverage ratios for substantially leverage increasing firms (1998-2010)

\begin{tabular}{lrrrrrrr}
\hline & $\mathbf{t}-\mathbf{3}$ & $\mathbf{t}-\mathbf{2}$ & $\mathbf{t}-\mathbf{1}$ & $\mathbf{t}$ & $\mathbf{t + 1}$ & $\mathbf{t + 2}$ & $\mathbf{t + 3}$ \\
\hline Market Leverage & 0.164 & 0.193 & 0.245 & 0.457 & 0.427 & 0.421 & 0.443 \\
Excess Leverage & -0.108 & -0.060 & -0.018 & 0.190 & 0.088 & 0.156 & 0.064 \\
\hline
\end{tabular}

The table presents the descriptive statistics for substantially leverage increasing firms publicly listed on Borsa Istanbul between the years 1998 and 2010. The firms covered are non financial firms, with data necessary for leverage calculations. The sample period covers 57 substantially leverage increasing firms. In order to be identified as a substantially leverage increasing firm, a firm needs to satisfy three requirements. It needs to have increased its market leverage at least $10 \%$ compared to the prior year's level. It also needs to have a new market leverage that is at least $10 \%$ above the target leverage that we have predicted. In addition, the firm is required to have increased its leverage ratio as a result of a debt increase, and not an equity decline. $t$ denotes the year of the substantial leverage increase. Market leverage is defined as total debt over the sum of total debt and market value of equity. The excess market leverage is defined as the difference between the firm's actual leverage ratio and the proxy for long run target leverage ratio. The target market leverage ratio is estimated using a double-sided tobit regression model censored at 0 and 1 for each year.

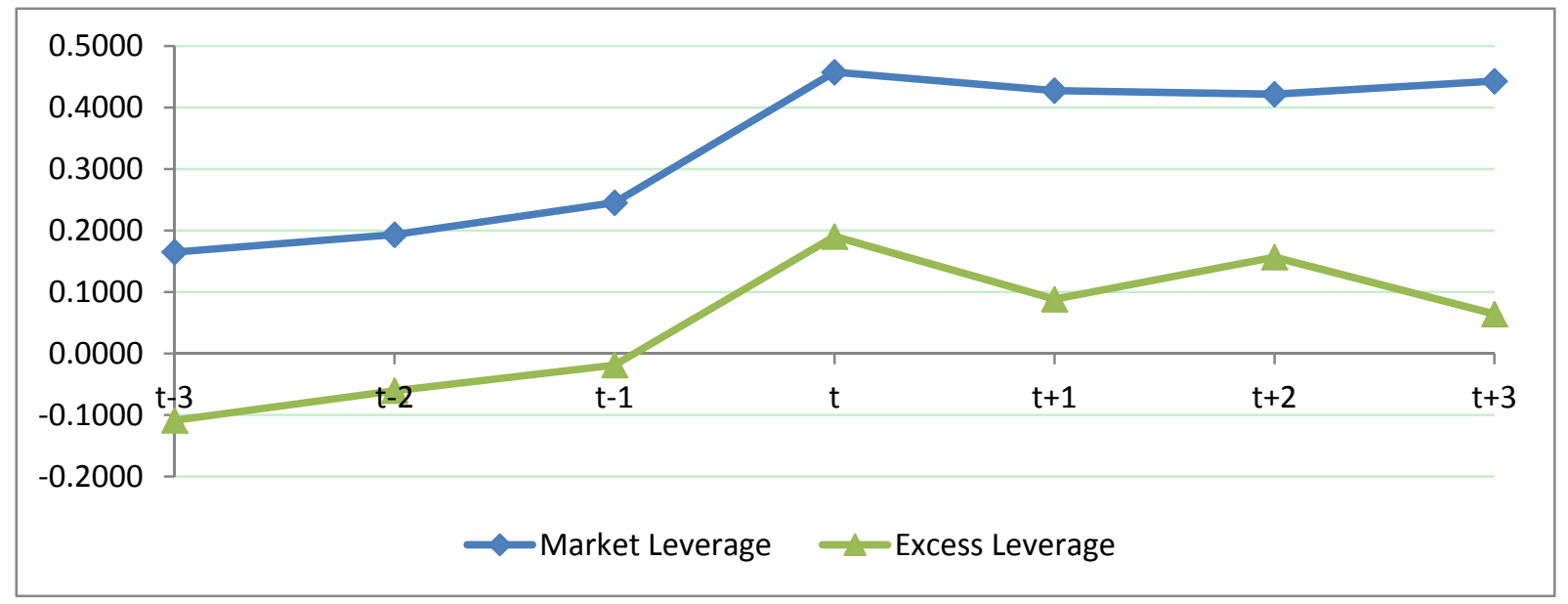

Figure 1. Evolution of leverage ratios for substantially leverage increasing firms (1998-2010)

The figure presents the behavior of market leverage and excess market leverage for substantially leverage increasing firms publicly listed on Borsa Istanbul between the years 1998 and 2010. The firms covered are non financial firms, with data necessary for leverage calculations. The sample period covers 57 substantially leverage increasing firms. In order to be identified as a substantially leverage increasing firm, a firm needs to satisfy three requirements. It needs to have increased its market leverage at least $10 \%$ compared to the prior year's level. It also needs to have a new market leverage that is at least $10 \%$ above the target leverage that we have predicted. In addition, the firm is 
required to have increased its leverage ratio as a result of a debt increase, and not an equity decline. $t$ denotes the year of the substantial leverage increase. Market leverage is defined as total debt over the sum of total debt and market value of equity. The excess market leverage is defined as the difference between the firm's actual leverage ratio and the proxy for long run target leverage ratio. The target market leverage ratio is estimated using a double-sided tobit regression model censored at 0 and 1 for each year.

The first row of Table 3 presents the evolution of median market leverage around the time of the substantial leverage increase. From time t-3 to t-1, we observe an increase in median market leverage levels. At the time of the substantial leverage increase, we observe a substantial jump in market leverage levels, which would be expected as a result of the nature of the substantial leverage increasing firms subsample. However, what is interesting is the pattern of the median excess leverage levels, which shows the deviation of leverage levels from target leverage levels. We observe that the excess market leverage levels start decreasing three years before the substantial leverage increase and make a substantial jump at the time of the substantial leverage increase. This behavior is also visualized in Figure 1.

To investigate the behavior of the market leverage levels more formally to derive at conclusions regarding the deviation from target leverage levels, we conduct two bootstrap simulations. The details of these simulations are discussed in the previous section. The results of the bootstrap analysis are presented in Figure2 and Figure 3. What we observe in both Figure 2 and Figure 3 is that the leverage levels of firms in substantially leverage increasing sample deviate from target leverage levels. The striking evidence is the behavior of leverage levels before the substantial leverage increase. The firms in our subsample have market leverage levels below the target leverage levels. By the leverage increase, their market leverage ratios make a substantial jump and this time they are above target leverage levels. The pre-jump behavior could be explained by firms' valuing the option to borrow highly and thus keeping their leverage levels below target leverage levels. When they have a motivation to increase their debt substantially, this time they deviate and move their leverage levels above target leverage levels.

The behavior of these firms, in terms of issuing debt to deviate from target leverage levels do not fit the predictions of tradeoff theory. However, their behavior is in accordance with the transitory debt model. In addition, the finding that debt issues do not reduce the deviation between their actual and target leverage levels, and actually increases the deviation also support the evidence in Hovakimian (2006).

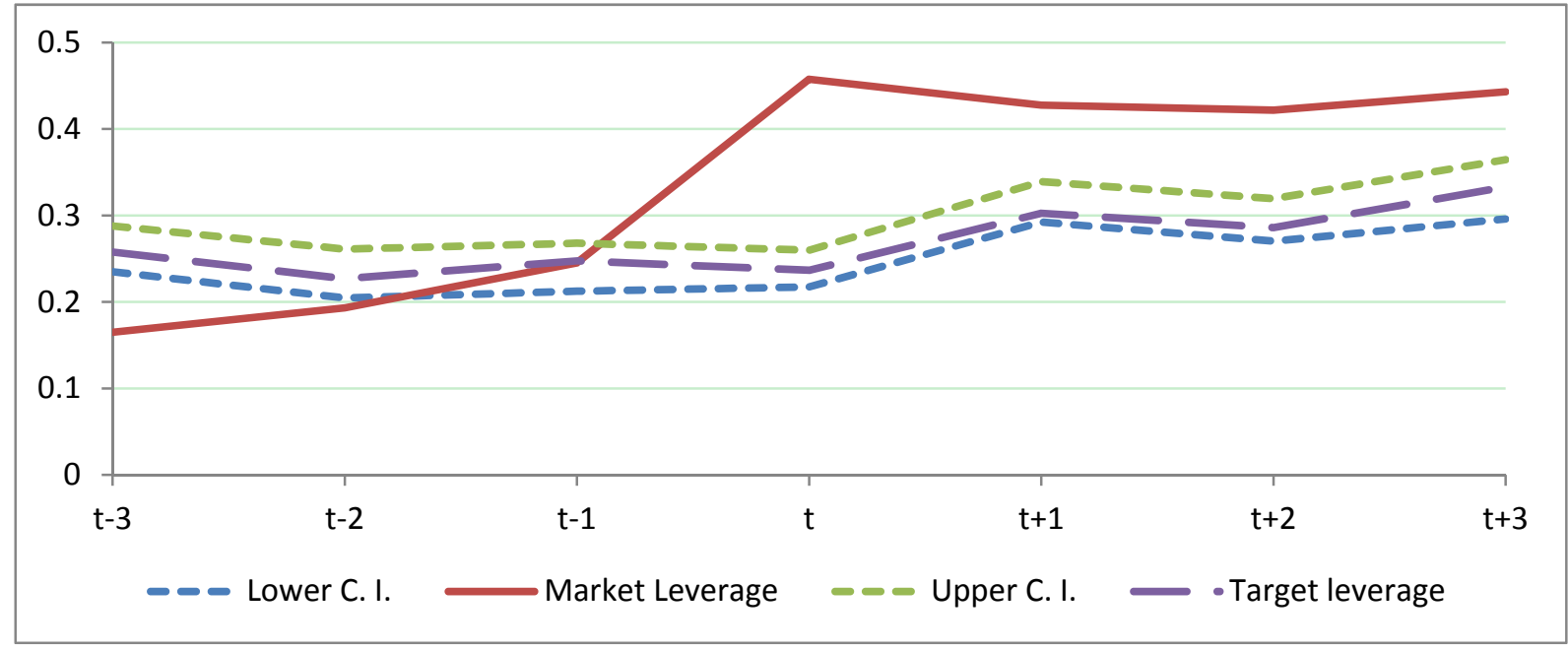

Figure 2. Market leverage, target leverage and bootstrap confidence intervals derived by percentile intervals method

The Figure shows the evolution of the market leverage, target leverage (medians) and its $95 \%$ confidence intervals for the firms in our substantially leverage increasing sample, between 1998 and 2010. The year of the substantial leverage increase is denoted as t. Market leverage is defined as total debt over the sum of total debt and market value of equity. The target leverage is estimated by a double-sided tobit regression censored at 0 and 1 . To derive the bootstrapped confidence intervals, the median target leverage is randomly sampled with replacements for 1,000 times.

The next and the last step of our analysis is to investigate the motivation underlying the substantial leverage increase that causes these firms to deviate from target leverage levels, as opposed to the predictions of tradeoff theory. 
The results of our analysis regarding the main motivation underlying substantial leverage increases are presented in Table 4. What we observe in Table 4 is that out of 57 firms, for which we are able to identify the main motivation underlying the substantial leverage increase, 18 of them increased leverage for investment purposes, 6 of them for operating cash flow purposes, 1 for payout purposes and finally 32 for working capital purposes.

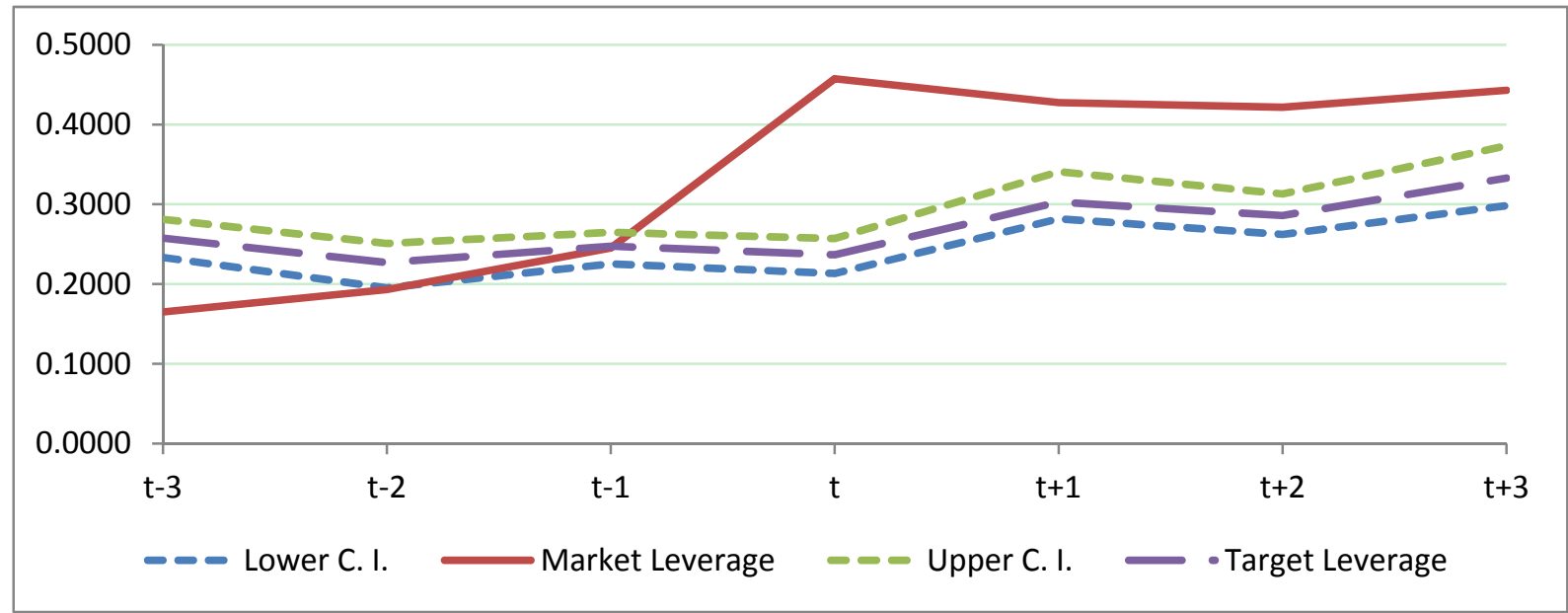

Figure 3. Market leverage, target leverage and bootstrap confidence intervals derived by bias corrected and accelerated confidence intervals method

The Figure shows the evolution of the market leverage, target leverage (medians) and its $95 \%$ confidence intervals for the firms in our substantially leverage increasing sample, between 1998 and 2010. The year of the substantial leverage increase is denoted as t. Market leverage is defined as total debt over the sum of total debt and market value of equity. The target leverage is estimated by a double-sided tobit regression censored at 0 and 1 . To derive the bootstrapped confidence intervals, the median target leverage is randomly sampled with replacements for 1,000 times.

Table 4. Main motivation for the substantially leverage increasing firms

\begin{tabular}{lcc}
\hline Motivation & \# of firms & Percentage \\
\hline Investment & 18 & 0.281 \\
Operations & 6 & 0.093 \\
Payout & 1 & 0.015 \\
Working Capital & 32 & 0.500 \\
None & 7 & 0.109 \\
\hline Total & $\mathbf{6 4}$ & $\mathbf{1 . 0 0 0 0}$
\end{tabular}

The table presents the descriptive statistics for substantially leverage increasing firms publicly listed on Borsa Istanbul between the years 1998 and 2010. The firms covered are non financial firms, with data necessary for leverage calculations. The sample period covers 57 substantially leverage increasing firms. In order to be identified as a substantially leverage increasing firm, a firm needs to satisfy three requirements. It needs to have increased its market leverage at least $10 \%$ compared to the prior year's level. It also needs to have a new market leverage that is at least $10 \%$ above the target leverage that we have predicted. In addition, the firm is required to have increased its leverage ratio as a result of a debt increase, and not an equity decline. $t$ denotes the year of the substantial leverage increase. Operations cover the use of debt issue proceeds for covering operational cash shortfalls. Payout covers the debt issue proceeds used for the purpose of paying out to stockholders. Working Capital covers the change in working capital $(\triangle \mathrm{WC})$ that is used for funding working capital needs. Investment covers the funds used for investment opportunities.

These findings are somewhat surprising compared to the findings of studies conducted for US markets, by Denis and McKeon (2012) and Gombola and Arioglu (2013), both of which provide evidence suggesting that the main motivation for firms to issue transitory debt is investment purposes. However, our findings suggest that firms traded at Borsa Istanbul issue transitory debt mainly for working capital purposes, followed by investment purposes. In 
developed economies such as US economy it might not be very surprising to observe that firms would issue transitory debt and increase their leverage levels when they have valuable investment opportunities. However, based on our findings, we can suggest that, firms in Turkish economy are more likely to prefer short term debt in their debt structure, in order to invest in current assets, and they issue transitory debt in order to fund their investments in current assets and working capital rather than long term investments, for maturity matching purposes. Alternatively, these results could also be an outcome of the financing environment in Turkish economy. The inability of firms to find long term financing resources with feasible conditions could be forcing them to use short term resources, rather than the firms preferring short term resources themselves.

\section{Conclusions}

Numerous studies investigating the capital structure behavior of firms publicly listed on Borsa Istanbul and developed economies provide evidence suggesting that firms' financing behavior support tradeoff theory. The tradeoff theory's main predictions are that firms would have optimal capital structures and managers would adjust firms' leverage levels towards the optimal capital structure, in order to maximize firm value. However, DeAngelo et al. (2011) estimate a more recent capital structure model. The transitory debt model predicts that firms would temporarily but deliberately deviate from target capital structures by issuing transitory debt, mainly for investment purposes.

In this study, we investigate whether or not there is any behavior of publicly listed firms at Borsa Istanbul supporting the predictions of transitory debt model. We also investigate the potential main underlying motivation if publicly listed firms deliberately but temporarily deviate from target capital structures. More specifically, we investigate whether firms listed at Borsa Istanbul deviate from target capital structures when they have valuable investment opportunities or for other purposes, by analyzing a sample of publicly listed firms between 1998 and 2010 .

Our findings suggest that firms prefer to make majority of their investments in current assets, rather than fixed assets. In addition, we observe that the excess market leverage levels start decreasing three years before the substantial leverage increase and make a substantial jump at the time of the substantial leverage increase. These findings suggest that firms value the option to borrow and thus, prior to substantial leverage increases, they decrease their leverage ratios even below their target leverage levels. Two bootstrap simulations confirm these findings. This behavior of firms, in terms of issuing debt causing them to deviate from target leverage levels do not fit the predictions of tradeoff theory. However, their behavior is in accordance with the transitory debt model. We also investigate the main motivation underlying the substantial leverage increase that causes these firms to deviate from target leverage levels. Our findings suggest that firms substantially increase their leverage levels with the main motivation of working capital purposes, followed by investment purposes.

Studies conducted in developed economies such as US economy suggest that firms issue transitory debt and increase their leverage levels when they have valuable investment opportunities. However, our findings suggest that in Turkish economy firms usually prefer short term debt in their debt structure. Thus, firms could be expected to fund their investments in current assets and working capital rather than long term investments, for maturity matching purposes, through transitory debt issue, which would lead them to deviate from target leverage levels. Therefore, investment in working capital concerns could be considered more vital compared to longer horizon investment concerns, pointing out to potential shorter term focus of publicly listed Turkish firms. Alternatively, these results could also be an outcome of the financing environment in Turkish economy. The inability of firms to find long term financing resources with feasible conditions could be forcing them to use short term resources, rather than the firms preferring short term resources themselves. The common practice of firms using short term bank credit and rolling the debt over in Turkish economy could be considered as an evidence in support of the latter explanation for the financing behavior of firms publicly listed at Borsa Istanbul.

\section{References}

Arioglu, E., \& Tuan, K. (2013). Do Firms Follow Target Capital Structure? Evidence from Borsa Istanbul. Working Paper.

Arslan, O. (2005). A Study on the Capital Structure of the Turkish Real Sector Firms. Istanbul Universitesi Siyasal Bilgiler Fakultesi Dergisi, (33), 103-118.

Ata, H. A., \& Ag, Y. (2010). Firma Karakteristiginin Sermaye Yapısı Uzerindeki Etkisinin Analizi. Istanbul Universitesi Ekonometri ve Istatistik Dergisi, 11, 45-60.

DeAngelo, H., DeAngelo, L., \& Whited, T.M. (2011). Capital Structure Dynamics and Transitory Debt. Journal of Financial Economics, 99, 235-261. http://dx.doi.org/10.1016/j.jfineco.2010.09.005 
Denis, D., \& McKeon, S. (2012). Debt Financing and Financial Flexibility: Evidence from Proactive Leverage Increases. Review of Financial Studies, 25, 1897-1929. http://dx.doi.org/10.1093/rfs/hhs005

Fama, E.F., \& French, K. R. (2002). Testing Trade-off and Pecking Order Predictions about Dividends and Debt. The Review of Financial Studies, 15, 1-33. http://dx.doi.org/10.1093/rfs/15.1.1

Flannery, M.J., \& Rangan, K.P. (2006). Partial Adjustment toward Target Capital Structures. Journal of Financial Economics, 79, 469-506. http://dx.doi.org/10.1016/j.jfineco.2005.03.004

Frank, M.Z., \& Goyal, V.K. (2009). Capital structure decisions: which factors are reliably important? Financial Management, 38, 1-37. http://dx.doi.org/10.1111/j.1755-053X.2009.01026.x

Gombola, M., \& Arioglu, E. (2013). Target Capital Structure and Transitory Debt: Evidence from Reverse LBOs. Working Paper.

Harford, J., Klasa, S., \& Walcott, N. (2009). Do Firms Have Leverage Targets? Evidence from Acquisitions. Journal of Financial Economics, 93, 1-14. http://dx.doi.org/10.1016/j.jfineco.2008.07.006

Healy, P. M., \& Palepu, K. G. (1990). Effectiveness of Accounting-based Dividend Covenants. Journal of Accounting \& Economics 12, 97-123. http://dx.doi.org/10.1016/0165-4101(90)90043-4

Hovakimian, A. (2006). Are Observed Capital Structures Determined by Equity Market Timing? Journal of Financial and Quantitative Analysis, 41, 221-243. http://dx.doi.org/10.1017/S0022109000002489

Huang, R., \& Ritter, J. R. (2009). Testing Theories of Capital Structure and Estimating the Speed of Adjustment. Journal of Financial and Quantitative Analysis, 44, 237-271. http://dx.doi.org/10.1017/S0022109009090152

Kayhan, A., \& Titman, S. (2007). Firms' Histories and Their Capital Structures. Journal of Financial Economics, 83, 1-32. http://dx.doi.org/10.1016/j.jfineco.2005.10.007

Leary, M.T., \& Roberts, M.R. (2005). Do Firms Rebalance Their Capital Structures? The Journal of Finance, 60, 2575-2619. http://dx.doi.org/10.1111/j.1540-6261.2005.00811.x

Rajan, R. G., \& Zingales, L. (1995). What Do We Know about Capital Structure? Some Evidence from International Data. Journal of Finance, 50, 1421-1460. http://dx.doi.org/10.1111/j.1540-6261.1995.tb05184.x

Sayilgan, G., Karabacak, H., \& Kucukkocaoglu, G. (2006). The Firm-Specific Determinants of Corporate Capital Structure: Evidence from Turkish Panel Data. Investment Management and Financial Innovations, 3(3), 125-139. 